\title{
Oxygen isotope variability in unmelted micrometeorites from the Sør Rondane Mountains, East Antarctica
}

\author{
FLORE VAN MALDEGHEM ${ }^{1}$, BASTIEN SOENS ${ }^{1,2}$, FELIX \\ E.D. E.D. KAUFMANN ${ }^{3}$, MATTHIAS VAN GINNEKEN ${ }^{4}$, \\ LUTZ HECHT $^{3}$, PHILIPPE CLAEYS ${ }^{1}$ AND STEVEN \\ GODERIS $^{1}$
}

${ }^{1}$ Vrije Universiteit Brussel

${ }^{2}$ Université Libre de Bruxelles

${ }^{3}$ Museum für Naturkunde

${ }^{4}$ University of Kent

Presenting Author: flore.van.maldeghem@vub.be

The study of cosmic dust and specifically unmelted micrometeorites constrains the nature of the interplanetary dust complex and contributes to optimizing analytic procedures for (future) sample-return missions. Unmelted micrometeorites are thought to experience limited thermal alteration during atmospheric entry and therefore mostly preserve the primary mineralogies and textures of their parent bodies [1]. Unmelted particles are relatively rare and small, causing challenges in their recovery and study.

In this work, we systematically characterized 50 unmelted micrometeorites ranging in size between 100 and $400 \mu \mathrm{m}$ containing a range of refractory (e.g., spinel) and relict (e.g., olivine and pyroxene) minerals. All particles were recovered from high-altitude sediment traps in the Sør Rondane Mountains (SRM, East Antarctica). Triple-oxygen isotope ratios were obtained for both matrix and minerals in each of the sectioned micrometeorites, using a Cameca IMS 1207 ion microprobe at the CRPG in Nancy (France) [2]. Based on a comparison with fully melted cosmic spherules (CSs) from the SRM, all major oxygen isotope groups observed for CSs and linked to chondrites are present. The ${ }^{16} \mathrm{O}$-poor group is also represented among these unmelted particles [2-3]. Different to previous work, several data points indicate a shift towards more negative $\delta^{18} \mathrm{O}$ values, possibly due to mixing with Antarctic precipitation during terrestrial alteration [4]. To confirm and refine the parentage and alteration history of the unmelted micrometeorites, individual minerals and phases with an offset to lighter oxygen isotope values have been studied using the JEOL JXA-8500F Electron Microprobe Analyzer at the Museum für Naturkunde Berlin (Germany). The elemental compositions support more extensive alteration of the recoverd unmelted micrometeorites than previously considered, with alteration effects likely occurring at the mineral scale.

References:

[1] Van Ginneken et al. (2012), Meteorit. Planet. Sci., 47, 2, 228247.

[2] Suavet et al. (2010), Earth Planet. Sci. Lett., 293, 313 - 320.

[3] Goderis et al. (2020), Geochim. Cosmochim. Acta, 270, $112-$ 143.

[4] Suttle et al. (2020), Earth Planet. Sci. Lett., 546, 116444. 